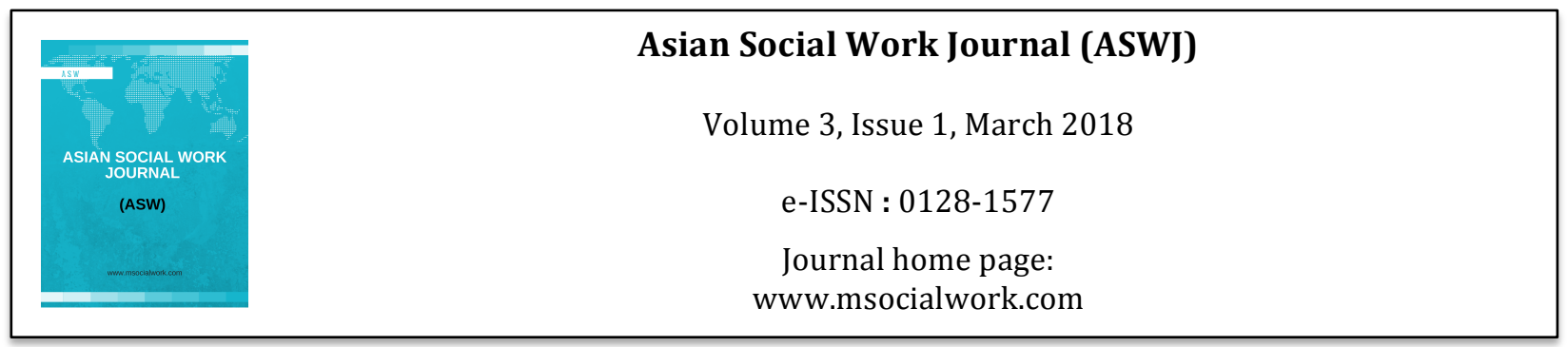

\title{
Emotions, Emotional Intelligence and Professional Practice in Caring Professions
}

\author{
Habibie Bte Hj Ibrahim ${ }^{1}$, Norhamidah Jarimal ${ }^{1}$, Nurul Hudani Md Nawi ${ }^{1}$, Puteri Hayati Megat \\ Ahmad $^{1}$ \\ 1Faculty of Psychology and Education, Universiti Malaysia Sabah (UMS)
}

Corrrespondence: Habibie Bte Hj Ibrahim (hibrahim@ums.edu.my)

\begin{abstract}
This paper based on literature review relates to emotions, emotional intelligence (EI) and their contributions to working relationships and decision-making processes are explored, particularly in social work settings. Little research has been conducted regarding emotion and Emotional Intelligence in the social work context. However, other caring professions such as health and nursing placed great emphasis on the importance of EI in their practice. Illness and healing processes occur within the context of relationships, and relationships are important frameworks for conceptualizing health care. This paper therefore aims to reveal the potential contributions of EI to working relationships with clients and decision-making processes in social work. This paper may provide some useful information for individuals and organizations as to how they can benefit from such contributions in order to develop more effective social work practices.
\end{abstract}

Key words: emotion, emotional intelligence, caring profession, professional practice

\section{Introduction}

In caring profession especially in the health care professions, illness and healing processes occur within the context of relationships, and relationships are important frameworks for conceptualizing health care. According to Beach, Inui and the Relationship-Centered Care Research Network (2005), a process occurs when patients realize the importance of working relationships between patients and nurses. They also propose four principles in relationship-centered care: 1) relationships in health care ought to include the personhood of the participants, 2) affect and emotions are important components of these relationships, 3) all health care relationships occur in the context of reciprocal influence, and 4) the formation and maintenance of genuine relationships in health care are morally valuable (2005:53). Ritter, Bowden, Murray et al. (2002) state that in the context of drug and alcohol treatment, the quality of therapeutic relationships is a main factor in helping the engagement of treatment and can also bring about changes in behavior (in Morrison, 2006). The Nurses Association of New Brunswick (2002) suggests that a therapeutic relationship involves working with four components: power, trust, respect and intimacy (in Morrison, 2006). Morrison quotes the Nurses Association of New Brunswick (2002) as saying that in establishing a therapeutic relationship, a nurse offers clients the following: 1) dedicated time, 2) full attention, 3) commitment to helping them get their needs met, 4) a supportive, boundary and ethical relationship, 5) empathy, 6) a suspension of normal moral judgement, and 7) reflective comments or feedback. These components can also be applied in social work practice where they could enhance client's trust of social workers. Thus, EI continues to be a topic of interest in the helping professions, particularly in medicine and nursing (McQueen, 2004). However, in the social 
work profession, there has been little investigation into its contributions, and few reports on its contributions have been issued.

There is an attempt by Morrison (2007) to propose the potential relevance of emotions and EI in relation to the five core social tasks of engagement, assessment, decision-making, collaboration and dealing with stress in social work. Howe (2008), in addition, discusses the emotional well-being of social workers and their clients, and examines how EI can affect mental and physical health. The term EI is quite new in the arena of social work, but some literature is concerned with relationship-based practice (Rogers, 2004), reflective and collaborative models of assessment (Wilson, Ruch, Lymbery and Cooper, 2008), the strength-based perspective (Saleebey, 2006), communication skills (Lefevre, 2010; Wilson et al., 2008; Koprowska, 2008) and reflective practice (Wilson, et al., 2008), which is relevant to EI and social work.

The concept of relationship-based practice has been introduced as a way of helping practitioners to begin to negotiate the complex web of relationships of which social work is comprised. It is not a new phenomenon and it has a strong connection with long-established psychosocial approaches to practice (Wilson et al., 2008). The strength-based perspective requires a significant alteration in how professionals actually understand and think about those with whom they work, how they think about themselves as professionals and the nature of the knowledge base for their practice (see Blundo, 2006). This is a significant shift for some social work practitioners. The unconscious motivations and defenses in clients must be understood and overcome. When social workers believe in clients' possibilities and potential and work together with them to make a life for them that moves them towards their dreams and goals, the human capacity for thriving stands out even in the most painful and difficult circumstances.

The strength perspective offers a way for social workers to move beyond the role of therapy to connect more deeply with the broad roles and goals of social work (Weick, Kreider \& Chamberlain, 2006). Throughout the development of strength-based work, the importance of relationship in helping efforts has been a constant theme. The nature of relationship has been recognized as the medium through which changes occur. For a professional practitioner to fully appreciate the implications of the strength-based perspective, it is necessary for him or her to engage in a personal analysis just as if he or she were attempting to shift 'automatic thoughts' or engaging 'unique outcomes' as alternative narratives to the dominant professional perspective (Blundo, 2006). This requires a competency in understanding and recognizing others' emotions. Therefore, understanding others' emotions is essential to a successful interpersonal relationship.

It has been argued that assessment practice needs to reinforce rather than reduce the importance of both intrapersonal and interpersonal skills (Morrison, 2007). Creative and collaborative assessments are important and ethical professional approaches. Such approaches to assessment recognize the expertise and experiences of those with whom the assessment is completed, and they are potentially necessary and efficient within the resource-deficient contexts in which social work is located. Together with professional identity, social workers are required to work in partnership with their clients and engage in mutually agreed and understood conversations. In an effort to identify the difficulties faced by clients, social workers need to work effectively and realistically. Additionally, the complexity of the tasks must not be underestimated, nor the need for well-developed interpersonal and organizational social work skills (see Wilson et al., 2008). Due to these considerations, social workers need to be well aware of the factors that contribute to a successful relationship process.

\section{Emotions and Human Relationships}

Emotions are thought to be one of the factors that have a large influence on relationships (Scheff, 2006). It has been argued that societies, for example, are intimately held together by positive emotions that people feel towards social structures and cultures, and conversely societies can be torn apart and changed by the arousal of both negative and positive emotions (Turner, 2007). Emotions are said to be the energy that is generated by biological and transactional needs; they are nonetheless implicated in 
meeting these biosocial needs. More importantly, emotions represent an independent source of motivational energy - above and beyond biosocial needs - that has a great effect on the structures and cultures of a society (Turner, 2007). At the micro level, it also suggests that in their interaction with others individuals should have certain kinds of emotions that can tie individuals together. Individuals' emotions also articulate their personal relationships and understanding of the world (Salovey \& Mayer, 1998). Turner (2007) proposes that one of the ingredients of strong ties and solidarity is increasing the arousal of positive emotions. Furthermore, Turner suggests that by increasing humans' emotionality, it will be possible to create a new way to generate stronger social bonds; however, three of the four primary emotions (i.e. anger, fear and sadness) are negative and do not bind individuals together. Other, more dangerous emotions such as vengeance and righteousness are also generated by the combination of anger and happiness, and these emotions can fuel violence and disruption of social bonds.

Goffman (1967, in Scheff, 2006) focuses on the emotional/relational world (ERW) - what might be called the micro-world of emotions and relationships. Scheff agrees with Goffman regarding the ERW and suggests that one of the main reasons that Goffman's work on emotions is important is that if people are to have more than a passing understanding of themselves and their society they need to become better acquainted with the ERW. However, Scheff also criticises Goffman's ideas regarding emotions. According to Scheff, Goffman only concentrates on embarrassment, shame and disgust. Scheff argues that Goffman has almost nothing to say about other important emotions, such as fear, pride and love. Scheff has argued that Goffman's approach to relationships is only based on negative relationship outcomes such as loneliness, disconnectedness and alienation, but positive relationship outcomes such as solidarity, secure bonds and moments of profound unity are omitted. With regard to young children in care, the relationships between social workers and children are said to be related to social workers' personal attitudes and values regarding children and childhood (Winter, 2009). In professional relationships, active and dynamic engagement can lead to the development of a bond that facilitates next steps (Dunkle \& Friedlander, 1996; Viederman, 2002). Meanwhile, in the context of decision-making, there is evidence that feelings and emotions experienced during decision-making can have positive effects on decision-making performance (Seo \& Barret, 2007). Isen, Daubman and Nowicki's (1998) research findings show that positive affect has a bearing on interpersonal problem solving. Creation and maintenance of good interpersonal relationships often involves finding ways of resolving disputes or negotiating arrangements of various kinds. When these would benefit from a creative approach, positive feelings might facilitate interpersonal processes (Isen et al., 1998).

Segal and Jaffe (2008) state that building relationships involves difficult and complex emotions. It is suggested that these difficult and complex emotions have an effect on everyone involved in nearly any type of relationship. Moreover, it has been argued that through exposure to complex relationships, individuals gain a better understanding of emotional expression and social competence (Segal \& Jaffe, 2008). Carr (2004, as cited in Saarni, 1997) discusses this idea further by connecting emotions to relationships and relationships to emotions. It has been argued that EI is important in forming successful human relationships (McQueen, 2004; Schuette et al., 2001). For example, Schuette et al. (2001) conducted seven studies on EI and interpersonal relations. Their research findings show that EI is connected to interpersonal relations, where higher scores for EI are related to higher scores for empathic perspective, social skills, cooperative response towards their partners, inclusion and affection, and satisfaction in relationships with prospective partners. Carr (2004) cites the work of Saarni (1997), who emphasises how being emotionally intelligent begins and ends with one's social and cultural environments because one's social environment defines his or her emotional maturity and appropriateness. If people cannot emotionally interact with and relate to their peers, they will not be able to understand the social world around them effectively. Lopes, Salovey and Straus (2003) state that EI is significantly correlated with several indicators of quality of social interaction. Furthermore, EI has been shown to have an effect on important life outcomes such as forming satisfying personal relationships and achieving success at work (Salovey \& Grewal, 2005). It has also been suggested that researchers need to take into account both emotional skills and personality in order to understand social and emotional adaptation (Lopes et al., 2003). In the social work profession, and particularly when working in partnerships, it has been argued that, as social workers deal with clients who are considered fragile, they need to understand the clients' situations and their levels of emotion. Howe (2008) 
suggests that emotionally intelligent social workers will most likely create therapeutically positive relationship environments. Hence, it seems that EI might be an important quality in social work. In the next section, this concept will be more fully explored.

\section{EI and Working Relationships}

Social workers' understanding of their own and others' emotions can assist them in building good relationships with clients. Some writers have also suggested that workers derive emotional benefits from their relationships with service users, in which they include feelings of closeness and being sustained, and develop a sense of spirituality and learning about themselves (Warwick, 2005). Baron (2000) argues that there is a correlation between the ability to be aware of emotions and the ability to create and maintain interpersonal relationships. According to Baron (2000), this correlation is probably related to the specific way in which the construct is defined. Baron also suggests that the ability to give and receive emotional closeness in relationhips is dependent not only on the ability to be aware of emotions, but also on the ability to understand feelings and emotions within those relations. It is important to understand how working relationships link with the concept of EI. EI within intrapersonal and interpersonal relationships can help social workers accurately perceive, understand, monitor and manage information effectively for themselves and their clients.

Morrison (2007), in his conceptual paper regarding EI and its impact on social work practice, considers EI and emotions in relation to five core tasks, which are 1) engagement of users, 2) assessment and observation, 3) decision-making, 4) collaboration and cooperation, and 5) dealing with stress. It is argued that at a time when social work needs to identify its claims to professional competence, one way to do this is to demonstrate the ability to use relationships to address users' needs. This requires the capacity to handle both one's own and others' emotions effectively (Morrison, 2007:245).

Assessment in social work involves a number of activities that include identifying, collating, assessing and analysing information and developing a plan of intervention (Wilson et al., 2008). Normally, professional relationships between social workers and clients will be formed within the assessment processes. Skills in communication are important as they are central to all relationships (Wilson et al., 2008) apart from the intra- and interpersonal skills, which could ensure that the assessment process goes well (Morrison, 2007). Assessment of complex cases of child abuse and neglect is a difficult and taxing process (Howe, Dooley \& Hinings, 2000). This requires not only skills in collection of information, but also all the skills mentioned above, which need to be utilised in order to provide effective and appropriate services to clients.

Practitioners in the social work profession deal with troubled individuals, families, groups and communities who are in need. Working with people who are in need requires that social workers give thought to issues of resilience and coping strategies (Morrison, 2007). Developing resilient personalities with good self-esteem and a sense of self-control is one of the strategies that has been encouraged in order to empower social workers to combat stress (Collins, 2008). Storey and Billingham (2001) note that high levels of stress are prevalent within the workplace. Stress is considered dangerous, not only to practitioners' health but also to the service that practitioners provide to users (Storey \& Billingham, 2001). Practitioners' characteristics, such as age and gender, are associated with stress in the workplace (Chadsey \& Beyer, 2001): research conducted by Storey and Billingham (2001) found that practitioners aged 45 years or younger appeared to have a higher level of stress than individuals aged over 45 , while females were reported to have higher levels of stress than males.

Besides characteristic factors, a good interpersonal relationship between practitioners and patients/clients is also important and very much needed as it can affect their practice. For example, research regarding nursing practice has shown that the opportunity to write nursing notes decreases the likelihood of nurses' stress because of problems in interpersonal relationships (Makinen et al., 2003). Writing nursing notes is common in patient-focused nursing mode. Makinen et al. (2003) add that stress from high levels of responsibility is associated with work overload and problems in interpersonal 
relations. Another stressor of practitioners in helping professions is fraught relationships between practitioners, managers and lawyers (Dickens, 2006). The different responsibilities, priorities and practices in these groups could compete. For example, new social workers who are less experienced may seek more help from lawyers but could be resented by managers due to costs.

The relationship between social workers and young children in care services is related to the social workers' personal attitudes and values regarding children and childhood (Winter, 2009). In professional relationships, active and dynamic engagement can lead to the development of a bond that facilitates the completion of next steps (Viederman, 2002). In the context of decision-making, there is evidence that feelings and emotions experienced during decision-making can have positive effects on decision-making performances (Seo \& Barret, 2007).

A child's welfare is best met within his or her own family, in which social and psychological development is fostered (Howe, 2005; Ballou et al., 2001; Sara, Jay \& Keith, 1992). The author considers that children's voices need to be heard alongside those of their parents; in addition, their wishes and feelings also need to be considered in working together. Winter (2009) emphasizes that it is important for social workers to develop long-term and consistent relationships with young children in whose lives they are involved. Inevitably, managing competing issues in such situations can lead to stress in social workers. In the UK, it is considered important, and it is emphasized within the legislation, that social workers work in partnership with parents by engaging them in decision-making (Lord Laming, 2009), and taking children's wishes and feelings into account is a key activity. The significance of effective and appropriate relationships has been highlighted as an important factor, not only in working with families but also in learning environments and in the development of relationship competency between social work students and their practice teachers (Lefevre, 2005). This demonstrates how the concept of relationship is important in the social work profession. More importantly it has been argued that relationships can only be conducted with skill and compassion if the social workers are emotionally intelligent (see Howe, 2008).

\section{EI and Decision-making Processes}

Decision-making is one of the core tasks in social work practice. Child and family social workers routinely make decisions that affect clients' lives. In this case, social workers are required to make good decisions that suit the clients' desires and needs. Working with children and their families requires the social workers to address the parents' needs as well as those of the children, as both parties often require attention. When social workers begin to think about children, they may be confronted with dilemmas. For instance, social workers have to focus on the children's needs while attending simultaneously to the family circumstances in which they are located (Wilson et al., 2008). Power is one of the principles of effective relationship-based social work with children and families. Wilson et al. (2008) argue that one of the main reasons for emotions running so high in social work with children and families is the statutory responsibilities of childcare social workers, which allow them to remove children from their families under certain circumstances.

Some researchers have viewed emotions as a dimension in decision-making (see Damasio, 2006; DeSousa, 1987). There seem to be situations in which emotions can enhance decision-making processes even though it is widely believed that the influence of emotions on reasoning would create problems. The researcher posits that whether emotions are functional or dysfunctional for decisionmaking depends on how social workers experience their emotions and what they do about them during decision-making.

In this section, the literature on decision-making in social work and other professions, covering cognitive biases and heuristics, alongside the impact of intuitions and emotions, is explored. Studies indicate that the brain uses two modes of reasoning: heuristic and analytic (see Hicks \& Kluemper, 2011). Heuristic reasoning has been categorized as intuitive, automatic and implicit processing, while analytic reasoning is referred to as deliberate, rule-based and explicit processing (Hicks \& Kluemper, 2011). If one's heuristic reasoning failed to produce a correct judgement, it would result in cognitive 
bias. Cognitive bias refers to systematic bias in the decisions people make, arising from the application of one or more heuristic processing (Lockton, 2012). Tversky and Kahneman (1974) argue that cognitive bias stems from a reliance on judgemental heuristics, which refers to the study of people's judgement under conditions of uncertainty.

In the social work profession, the terms 'judgement' and 'decision-making' are often used interchangeably. However, according to Taylor (2010:10), professional judgement is when "a professional considers the evidence about a client or family situation in the light of professional knowledge to reach a conclusion or recommendation", while decision-making is defined as the selection of a course of action as a result of a deliberate process by one or more people. Professional decision-making in social work is argued to consist of various models of ethical decision-making which aim to encapsulate as many features (or steps) of the decision-making process but they are of limited use in day-to-day social work practice (Taylor, 2010).

Banks (2012) proposes ethical decision-making and ethical work by providing an essential reference point for professional decision-making (i.e. ethical, psychological, emotional, practical, technical and legal aspects are included in the decision-making processes). There is a suggestion that, in decisionmaking processes, decision-makers should employ a self-reflective attitude that incorporates selfmonitoring and disconfirming strategies into their daily work habits (Rogerson et al., 2011). According to Rogerson et al. (2011), emotions and values exert a powerful influence through automatic and intuitive processes. Acknowledging and understanding the resulting tendencies and biases forms a promising path to a more realistic, accurate and helpful conceptualization of decision-making, particularly in emotionally charged situations. This means that 'practice wisdom' calls for practitioners to heighten their reflective capacities in judgement processes (see Collins \& Daly, 2011). Collins and Daly (2011) add that intuition or 'gut feeling' may also have a key role in the use and development of practice wisdom. In The Social Work Dictionary, 'practice wisdom' is defined as "a term often used by social workers to describe the accumulation of information, assumptions, ideologies, and judgements that have seemed practically useful in fulfilling the expectations of the job" (in DeRoos, 1990:282).

The roles of cognitive biases and heuristics have been much discussed in medical decision-making. Because of the potential relevance of cognitive biases and heuristics to decisions made by both patients and clinicians, there is growing interest in studying them in the medical context (see Blumenthal-Barby \& Krieger, 2014; Croskerry, 2003). Cognitive Dispositions to Respond (CDRs) means removing the stigma of bias to clear the way towards accepting the capricious nature of decision-making, and perhaps they go some way towards exculpating clinicians when their diagnoses fail (Croskerry, 2003). In business management, heuristics are proposed due to the view that, for certain cognitive and environmental constraints, rationality is hardly possible, so heuristics rescue the manager from worrying about an urgent decision; thus, the dependence on shortcuts paves the way into the management's psyche while making the decision (Asadullah \& Muhammad Kundi, 2013). It is not certain whether heuristics are good or bad; however, there is a view that their accurate use depends on the situations and individuals in the organizations that rely on heuristics in an adaptive way (see Gigerenzer \& Gaissmaier, 2011). In addition, Khatri and Ng (2000) found that there is a positive relationship between intuitive synthesis and organizational performance in an unstable environment and vice versa, which means intuitive synthesis is an important strategy process factor that managers often exhibit in their strategic decision-making. There is also a view that some heuristics are highly efficient and can compete with complex decision models in some application domains - for example, depending on readily available internal information and gut feelings in order to avoid long-term delays (Albar \& Jetter, 2009). This strengthens the view that the most important role of emotions in decisionmaking is to guide behavioral decisions via motivational processes, allowing for fast actions (Zeelenberg et al., in Bohm, 2008). A recent study showed that there is an association between level of EI and decision-making. The study by Sumathy, Madhavi and Felix (2015) indicated that EI highly influenced the leader's decisions, and that decision-making was more highly influenced by the empathy dimension of EI. There is a negative meaningful relationship between EI and the rational decisionmaking style of managers and a positive meaningful relationship between EI and the intuitive decisionmaking style of managers (Moghadam, Tehrani \& Amin, 2011). 
Doyle, Miller and Mirza (2009) add that personal and professional factors are related to ethical decision-making among social workers. Personal factors that are related include ethnicity, religion and gender. On the other hand, professional factors that are related include commitment to social work values, education, and whether or not social workers have received formal ethics training. Doyle, Miller and Mirza (2009) also add that social workers sometimes make rational and ethical decisions based on rules and/or codes (codified), and at other times they tend to make decisions following factors other than the rules and/or codes (e.g. intuition). This means the social workers use both codified and non-codified rationales when dealing with ethical dilemmas. This seems to suggest that both approaches have a role to play in social work practices (see also O'Sullivan, 2011).

In light of the areas mentioned above, there is a greater understanding of the role that EI plays in social work practice; hence, there is potential to enhance this. Howe (2008) has discussed emotions in terms of their origins and impact on our judgement, behaviors and actions, and particularly the fundamental part emotions play in effective and responsive professional practice. Howe clearly illustrates the strong links between EI, professional relationships and skilled practice. In the first chapter of his book, Howe concludes that the emotionally intelligent social workers understand the part that emotions play in their own and other people's thoughts and feelings, hopes and beliefs, designs and plans, behavior and perceptions. They can use this knowledge with skill and sensitivity to engage with those in distress and difficulty. They are intelligent about what emotion is and how it can be managed, developed and used in the self and others (2008:8-9)

The quotation above suggests that social workers who have knowledge of emotions and competence in handling their own and others' emotions can build good relationships with clients. Developing good relationships may make it easier for clients to share their problems. When cooperation is present, the process of making decisions is made easier.

Economists suggest that the influence of emotions on decision-making processes is disruptive (Gordon, 1941; Paul, 1969; Curwin, 1985, 2002; Bhushan, 2004). They agree that elements of emotions should not be involved in decision-making processes, to the extent that decision-makers need to be rational enough to free themselves of any emotions. Emotions are also known as the 'affective aspect' of determining attitudes and being one of the predispositions of human behaviour. Principally, emotions portray human feelings in different situations. It has been argued that emotions enable decision-makers to avoid procrastination, which is one of the most important aspects of emotions that need to be considered (Cappelletti, 2005). Some scholars emphasise the need to consider anticipated emotions, where they are not experienced at the moments of choice, but are expected to occur when outcomes are experienced (Cappelletti, 2005). Consequently, psychologists, sociologists, economists and even physical scientists have become much more interested in studying emotions and decision-making in recent years (see Barnes \& Thagard, 1996; DeSousa, 1987; Damasio, 2006; Turner, 2007).

Some research studies on EI traits and decision-related emotions have been conducted by Sevdalis, Petrides and Harvey (2007). Their research focuses on individual differences in perceptions and experiences of emotions. Their research findings show a positive relationship between EI traits and the deterioration of moods, negative relationship between EI and negative emotions and positive association between EI and affective overprediction. Meanwhile, Gina (2005) tries to explain how EI can affect an outcome such as the use of different judgemental biases. Her research findings show significant relationships between the understanding of emotions and self-awareness and empathy; selfawareness and the ease of recall bias at item level; creativity and the sufficient anchor adjustment bias; perceptions of emotions and the ease of recall bias at item level; and understanding of emotions and the false consensus bias at item level. In addition, Isen (2000, as cited by Morrison, 2007) found that positive effect is related to mental capacities that have a direct impact on decision-making, which include expanded and creative thinking, ability to link different sources and types of information or ideas, better elaboration of information, greater flexibility in negotiation of situations and improved diagnostic/assessment ability.

Practices in social work require social workers to make decisions. Furthermore, professionalism demands the social workers do so in an informed and rational manner. Society, and particularly clients, 
expects that professionals will make decisions carefully and wisely by virtue of their knowledge and skill. Yet, evidence from the burgeoning field of decision-making research warns social workers that decision quality may be compromised by factors such as time pressures, emotions, cultural differences, lack of information and a wide range of alternatives. These factors are the rule rather than the exception for many contexts in which social workers make decisions (Meacham, 2007). In the profession of social work and child protection decision-making in particular, the author assumes that knowledge, analysis and high levels of skills are needed. Personal and societal factors also need to be considered. Decision-making in social work does not require a single skill but a complex cluster of skills, which include thinking skills and interpersonal skills that are concerned with processes at the micro, intermediate and macro levels (O'Sullivan, 1999). Substantial empirical research has emphasized the relevance of emotions in decision-making processes (Zeelenberg et al., 2008; Seo \& Barret, 2007; Barnes \& Thagard, 1996). Thus, there is evidence that EI is a predictor of ethical decision-making (Scott, 2005). Scott-Ladd and Chan (2004) have reviewed some of the literature on EI, organizational learning and participation in decision-making. They found that higher levels of EI are reputed to contribute substantially to higher performance outcomes and inter-group relations and are prerequisite for organizational learning. Consequently, it seems appropriate to suggest that the boundary between feeling and thinking and the oft-heard call for the removal of emotions from so-called objective or professional decision-making requires reassessment (see Morrison, 2007).

\section{Conclusion}

Emotions and EI have been debated in many contexts and their conceptualization remains contested. However, the development and organization of emotional processes and experiences, which could be argued to have biological underpinnings, have been said to be influenced, sustained or modified by the system of meanings in which one's self, other people, surroundings and social events or objects have made their contributions. Even though the biological approach is accepted in considering emotions, after reviewing the literature I also consider that culture makes a key contribution to how people express, regulate and utilize emotions.

In terms of EI, there is disagreement among scholars about whether EI is an ability that relates to cognition or to the personality traits of individuals. The different definitions of EI have been said to occur for various reasons. Scholars and researchers are still considering what they mean by EI. Some writers seek to split EI into two parts: intrapersonal intelligence and interpersonal intelligence. There are also a variety of tools that are used to measure EI and its performance in humans according to context, such as workplaces and universities as well as clinical and psychotherapeutic settings. Studies suggest that EI is important in human relationships, whereby through understanding of their own and others' emotions, individuals may be more able to understand and respect each other. Thus, the present research aims to investigate the concept of EI in a cultural context with the emphasis on intrapersonal and interpersonal relationships.

Research on EI in social work is still very limited, though it has been shown to be important in other caring professions. This paper therefore aims to reveal the potential contributions of EI to working relationships with clients and decision-making processes in social work. This paper may provide some useful information for individuals and organizations as to how they can benefit from such contributions in order to develop more effective social work practices.

\section{References}

Albar, F.M., and Jetter, A. (2009) Heuristics in Decision Making. In: Engineering and Technology Management Faculty Publications PICMET 2009 Proceedings. August 2-6, 2009. Portland, Oregon USA [online] Available at: $<$ file:///C:/Users/740122125420/Desktop/Fatima.pdf> [Accessed 29 Jan 2016] 
Asadullah, M., \& Muhammad Kundi, G. (2013). An analysis of the use of heuristics to understand the dynamics of modern decision making. International Journal of Business Management and Administration, 2(4), 64-68.

Ballou, M., Barry, J., Billingham, K., Boorstein, B.W, Butler, C., Gersberg, R., Heim, J., Liriano, D., McGovern, S., Nicastro, S., Romaniello, J., Vazquez-Nuttall, K. \& White, C. (2001). Psychological model for judicial decision making in emergency or temporary child placement. American Journal of Orthopsychiatry, 71(4), 416-425.

Banks, S. (2012). Ethics and Values in Social Work (4th ed.). Basingtoke: Palgrave Macmillan

Barnes, A. \& Thagard, P. (1996) Emotional Decisions. [online] Available at: $<$ http://cogsci.uwaterloo.ac/articles/Pages/Emot.Decis.html> [Accessed 11th February 2010]

Bar-On, R. (2000). Emotional and Social Intelligence: Insights From the Emotional Quotient Inventory. In: Bar-on, R. and Parker, J.D.A., eds. The Handbook of Emotional Intelligence. San Francisco: Jossey-Bass, 363-388.

Beach, M.C., Inui, T. \& the Relationship-Centered Care Research Network (2005). Relationshipcentered care: A constructive reframing. Journal of General International Medicine, 21(1), 3-8.

Blumenthal-Barby, J.S., \& Krieger, H. (2014). Cognitive Biases and Heuristics in Medical Decision Making: A Critical Review Using a Systematic Search Strategy. Medical Decision Making, 120.

Blundo, R. (2006). Shifting Our Habits of Mind: Learning to Practice From a Strengths Perspective. In: Saleeby, D., eds. The Strengths Perspective in Social Work Practice. (4th ed). Boston: Pearson A\&B, 25-45.

Bohm, G. \& Brun, W. (2008). Intuition and affect in risk perception and decision making. Judgement and Decision Making, 3(1), 1-7.

Bhushan, N. (2004) Strategic Decision Making: Applying the Analytic Hierarchy Process. London : Springer

Cappelletti, D. (2005). The Impact of Emotions on Probabilistic Decision Making: A Research Proposal. [online]. Available at: $<$ http://cifrem.economia.unitn.it/file2/researches/52_research_proposal_dc.pdf $>$ [Accessed 27th June 2009]

Chadsey, J. \& Beyer, S. (2001). Social relationships in the workplace. Mental Retardation and Developmental Abilities research Reviews, 7, 128-133.

Collins, E. \& Daly, E. (2011). Decision making and social work in Scotland: The role of evidence and practice wisdom. The Institute for Research and Innovation in Social Services (IRISS) [online] Available at: $<\quad \mathrm{http}: / / \mathrm{www}$.iriss.org.uk/sites/default/files/decision-making-wisdom-iriss2011.pdf $>$ [Accessed 29 Jan 2016]

Collins, S. (2008). Statutory social workers: Stress, job satisfaction, coping, social support and individual differences. British Journal of Social Work, 38(6), 1173-1193.

Crosskerry, P. (2003). The Importance of Cognitive Errors in Diagnosis and Strategies to Minimize Them. Academic Medicine, 78(8), 775-780.

Curwin, J. (1985) Quantitative Methods for Business Decisions. Wokingham: Van Nostrand Reinhold

DeRoos, Y.S. (1990). The Development of Practice Wisdom through Human Problem-solving Processes. Social Service Review, 64(2), 276-287.

Damasio, A. (2006). Descartes' Error: Emotion, Reason and Human Brain. London: Vintage

DeSousa, R. (1987). The Rationality of Emotion. London: The MIT Press

Dicken, J. (2006). Care, control and change in child care proceedings: Dilemmas for social workers, managers and lawyers. Child and family Social Work, 11, 23-32.

Doyle, O.Z., Miller, S.E., \& Mirza, F.Y. (2009). Ethical decision-making in social work: Exploring personal and professional values. Journal of Social Work Values and Ethics, 6(1), 1-9

Dunkle, J.H. \& Friedlander, M.L. (1996). Contribution of therapist experience and personal characteristics to the working alliance. Journal of Counselling Psychology, 43, 456-460.

Gigerenzer, G., \& Gaissmaier W. (2011). Heuristic Decision Making. Annu. Rev. Psychol, 62, 451-82

Gina, B. (2005). Emotional intelligence and decision making: The impact on judgment bias. Dissertation Abstracts International, 66: 5-B, 2863.

Goffman, E. (1967). Interaction Ritual. Chicago: Aldine

Gordon, G. (1941). Quantitative Decision Making for Business. London: Prentice-Hall 
Hicks, E.P., \& Klumper, G.T. (2011). Heuristic reasoning and cognitive biases: Are they hindrances to judgments and decision making in orthodontics?. American Journal of Orthodontist, 139:(3), 297-304

Howe, D. (2008). The Emotionally Intelligent Social Worker. New York: Palgrave MacMillan

Howe, D., Dooley, T. \& Hinings, D. (2000). Assessment and decision-making is a case of child abuse and abuse using an attachment perspective. Child and Family Social Work, 5, 143-155.

Isen, A.M., Daubman, K.A. \& Nowicki, G.P. (1998) Positive Affect Facilitates Creative Problem Solving. In: Jenkins, J.M., Oatley, K. and Stein.N.L., eds. Human Emotions: A Reader. Malden: Blackwell Publishers, 288-297.

Khatri, N., \& Ng, H.G. (2000). The role of intuition in strategic decision making. Human Relations, 53(1), 57-86.

Lefevre, M. (2005). Facilitating practice learning and assessment: The influence of relationship. Social Work Education, 24(5), 565-583.

Lockton, D. (2012). Cognitive biases, heuristics and decision-making in design for behavior change.

Lopes, P.N., Salovey, P. \& Straus, R. (2003). Emotional intelligence, personality, and the perceived quality of social relationships. Personality and Individual Differences, 35, 641-658.

The Lord Laming (2009). The Protection of Children in England: A Progress Report. [online] Available at: <htp://publications.everychildmatters.gov.uk/eOrderingDownload/HC-330.pdf $>$ [Accessed 12th February 2010]

Makinen, A., Kivimaki, M., Elovainio, M. \& Virtanen, M. (2003). Organization of nursing care and stressfull work characteristics. Journal of advanced Nursing, 43(2), 197-205.

McQueen, A.C.H. (2004). Emotional intelligence in nursing work. Journal of Advanced Nursing, 47(1), 101-108.

Meacham, G.M. (2007). Ethics and decision making for social workers. Journal of Social Work Values and Ethics, 4(3).

Moghadam, A.H., Tehrani, M. \& Amin, F. (2011). Study of the Relationship Between Emotional Intelligence (EI) and Management Decision Making Styles. World Applied Sciences Journal, 12(7), 1017-1025.

Morrison, T. (2007). Emotional intelligence, emotion and social work: Context, characteristics, complications and contribution. British Journal of Social Work, 37(2), 245-263.

Morrison, T. (2006) The Therapeutic Relationship. [online] Available at: $<$ http://www.alcoholdrugs.co.uk/themes/therapeutic\%20relationship.htm> [Accessed 9th November 2009]

Nurses Association of New Brunswick (2002). The Nurses Act. Fredericton, NB: Author

O'Sullivan, T. (2011). Decision Making in Social Work, 2nd eds. Basingstoke: Macmillan

Paul, J. (1969) Business Decision Theory. Maidenhead: McGraw-Hill

Rogers, C. (2004) A Therapist's View of Psychotherapy: On Becoming a Person. London: Constable \& Robinson Ltd

Ritter, A., Bowden, S., Murray, T., Ross, P., Greeley, J. \& Pead, J. (2002). The influence of the therapeutic relationship in treatment for alcohol dependency. Drug and Alcohol Review, 21, 261-268

Rogerson, M.D., Gottlieb, M.C., Handelsman, M.M., Knapp, S., \& Younggren, J. (2011). Nonrational Processes in Ethical Decision Making. American Psychologist Association, 66(7), 614-623.

Saarni, C. (1997). Emotional Competence and Self-Regulation in Childhood. In: Salovey, P. and Sluyter, D.J., eds. Emotional Development and Emotional Intelligence: Educational Implications. New York: Basic Books, 35-69.

Saleeby, D. (2006) The Strengths Perspectives in Social Work Practice (4th ed). Boston: Pearson

Salovey, P. \& Grewal, D. (2005). The Science of Emotional Intelligence. Current Directions in Psychological Science, 14(6), 281-285.

Salovey, P. \& Mayer, J.M. (1998) Emotional Intelligence. In: Jenkins, J.M., Oatley, K. and Stein. N.L., eds. Human Emotions. Malden: Blackwell Publishers, 313-318.

Sara, G., Jay, B. \& Keith, C. (1992). Marriage, parenting and child development. Journal of Family Psychology, 5(3-4), 276-294.

Scheff, T.J. (2006). Goffman Unbound: A New Paradigm for Social Science. London: Paradigm Publisher. 
Schutte, N.S., Malouff, J.M., Bobik, C., Coston, T.D., Greeson, C., Jedlicka, C., Rhodes, E. \& Wendrof, G. (2001). Emotional intelligence and interpersonal relations. The Journal of Social Psychology, 141(14), 523-536.

Scott, B.S. (2005). The relationship between emotional intelligence and ethical decision making. Dissertation Abstracts International Section A: Humanities and Social Sciences, 65: 8-A, 2899.

Scott-Ladd, B. \& Chan, C.C.A. (2004). Emotional intelligence and participation in decision-making: Strategies for promoting organizational learning and change. Strategic Change, 13, 95-105.

Segal, J. \& Jaffe, J. (2008). The Language of Emotional Intelligence. New York: McGraw Hill

Seo, M-G \& Barrett, L.F. (2007). Being emotional during decision making-Good or bad? An empirical investigation. Academy of Management Journal, 50(4), 923-940.

Sevdalis, N., Petrides, K.V. \& Harvey, N. (2007). Trait emotional intelligence and decision-related emotions. Personality and Individual Differences, 42, 1347-1358.

Storey, J. \& Bilinggham, J. (2001). Occupational stress and social work. Social Work Education, 20:(6), 659-670.

Sumathy, L., Madhavi, C., \& Felix, A.J.W. Influence of Emotional Intelligence on Decision Making by Leaders. American International Journal of Social Science, 4(1), 134-140.

Taylor, B.J. (2010). Professional Decision Making in Social Work. Exeter: Learning Matters Post Qualifying Social Work Series

Turner, J.H. (2007) Human Emotions: A Sociological Theory. Oxon: Rouledge

Tversky, A., \& Kahneman, D. (1974). Judgement under uncertainty: Heuristics and biases. Science, New Series, 185(4157), 1124-1131.

Viederman, M. (2002). Active engagement in the consultation process. General Hospital Psychiatry, 24, 93-100.

Warrick, T.G.W. (2005). How do relationships with service users affect the professional practice and emotional well-being of social care practitioners? What are the implications for supervision? MSc. Thesis. University of Bradford.

Weick, A., Kreider, J. \& Chamberlain, R. (2006). Solving problems from a strengths perspective. In: Saleeby, D., eds. The strengths perspective in social work practice. (4thed). Boston: Pearson $\mathrm{A} \& \mathrm{~B}, 116-127$.

Wilson, K., Ruch, G., Lymbery, M. \& Cooper, A. (2008). Social Work: An Introduction to Contemporary Practice. Essex: Pearson Education Limited

Viederman, M. (2002). Active engagement in the consultation process. General Hospital Psychiatry, 24, 93-100.

Winter, K. (2009). Relationship matter: the problems and prospects for social workers' relationships with young children in care. Child and Family Social Work, 14, 450-460.

Zeelenberg, M., Nelissen, R.M.A., Breugelmans, S.M. \& Pieters, R. (2008). On emotion specificity in decision making: Why feeling is for doing. Judgment and Decision Making, 3(1), 18-27. 